urgent need of removal from home for diagnostic, protective, or therapeutic reasons places in existing children's hospitals, or in hostels or other primarily non-medical child-care settings, may be more suitable than admission to a special school or unit, where, despite the fact that the majority of children rapidly become evidently less disturbed in their behaviour, the duration of stay may be as long as four years. ${ }^{10}$

Economic factors are in any case likely to slow the further growth of special units, and the competing demands for medical manpower make it unlikely that enough doctors of sufficient skill and experience will be available to staff a comprehensive child psychiatric service. Teachers and childcare and probation officers, and others directly concerned with child care, must continue to carry a considerable share of the management of disturbed children. Their training in the recognition and management of emotional disorders is improving, but their greatest need is for continuing consultation, guidance, and support in the management of their cases. Family doctors more than anyone have the opportunity to know families over many years and may be able to intervene before the development of overt disorder or to offer guidance in minimizing the effects of adverse situations. Unfortunately undergraduate and postgraduate education does little at present to equip the doctor for these tasks. Paediatricians and school medical officers are also more likely to see disturbed children than the specialized psychiatric services, but are often reluctant to attempt to deal with these problems because of their uncertainty about their own capacity to offer effective treatment and because of lack of available psychiatric consultation. Psychiatrists practising in clinics for adult patients are often untutored in the problems of childhood and adolescence, and when already involved with a family situation prefer to refer the younger members to a colleague working in another setting.

In these circumstances it would seem that child psychiatrists have an enormous responsibility for education and consultation. Perhaps they should sacrifice some of the pressures and satisfactions of individual therapy and spend more time giving training, consultation, and support to colleagues, both medical and non-medical, who are providing individual and family care in the community. At the same time they must try to ensure that adequate resources are invested in research. As well as including study of the origins and development of childhood disorders, this should be aimed at evaluating the consequences of different forms of treatment. Our present child psychiatric services are so rudimentary that the buildings and staffing patterns of the next decade may mould the development of services for the next century.

1 The Registrar General's Statistical Review of England and Wales for the Year 1960, Supplement on Mental Health, 1964. H.M.S.O.

2 Ministry of Health, H.M. (64) 4. H.M.S.O.

- Blacker, C. P., Neurosis and the Mental Health Services, 1946.

- Ministry of Education, Report of the Committee on Maladjusted Children, 1955. H.M. M. O.

- Howells, J. G., Family Psychiatry, 1963. Edinburgh.

- Caplan, G., Principles of Preventive Psychiatry, 1966. London.

Ryle, A., Proc. roy. Soc. Med., 1963, 56, 834.

Rutter, M., and Graham, P., ibid., 1966, 59, 382.

Shepherd, M., Oppenheim, A. N., and Mitchell, S., f. Child Psychol. Psychiat., 1966, 7, 39.

10 Royal Medico-Psychological Assoclation, Report on Schools and Hostels for Maladjusted Children, 1965. London.

\section{Which Hypotensive Drug?}

Hypotensive treatment improves the prospects of patients with severe hypertension, ${ }^{12}$ and it is thought possible that the degree of benefit is related to the effectiveness of control of the blood pressure.

Now that many hypotensive drugs are available, and more appear every year, it becomes increasingly difficult to decide which drug should be given to any patient. Indeed, the multiplication of remedies means that no single one is entirely satisfactory. Side-effects and other hazards must always be balanced against possible benefits.

The drugs used will depend in part on the patient's condition. In hypertensive emergencies, such as encephalopathy or left ventricular failure, the blood pressure must be reduced rapidly. For this purpose parenteral hexamethonium or pentolinium may be given, provided the patient is either sitting up or tilted feet downwards. Intramuscular reserpine or intravenous frusemide or ethacrynic acid may likewise be employed unless there is reason to believe that the patient has obstructive disease of the urinary tract or severe renal failure. Parenteral treatment with methyldopa has been advocated, but it can occasionally cause a transient rise of arterial pressure ${ }^{3}$ and is probably better avoided. Patients requiring this kind of treatment will almost invariably need continuous control of their blood pressure thereafter unless the emergency is due to a self-limiting condition such as acute glomerulonephritis.
The drug chosen for maintenance treatment of hypertension will also depend to some extent on the patient's state. Patients with severe or malignant hypertension will usually require one of the more potent sympathetic blocking agents, while the blood pressure of patients with milder disease can often be controlled with drugs that require less meticulous attention to dosage. Phenobarbitone has no place in the treatment of hypertension. ${ }^{5} \quad$ A thiazide type of diuretic is usually the first choice for patients with mild hypertension provided there is no risk from gout or diabetes. There is no evidence that any single diuretic is superior to the others in respect of efficacy or freedom from side-effects. There is little point in increasing the dose if adequate control of the blood pressure is not achieved. Potassium supplements will be required, particularly if the patient- is receiving digitalis. If adequate control is not obtained, it is probably reasonable to add small doses of a rauwolfia alkaloid. This combination is usually more effective than a diuretic alone, though the rauwolfia alkaloid may cause depression or retention of sodium. There is again no unequivocal evidence that one rauwolfia compound is superior to the others. One major advantage of diuretics and rauwolfia compounds is that they do not cause postural hypotension. The same is true of propranolol, which has a moderate hypotensive action. ${ }^{\circ}$ It may, however, cause cardiac failure, and its place in the routine treatment of hypertension is not yet established.

If the above drugs fail to control the blood pressure, or if the patient has severe hypertension, one of the agents affecting 
sympathetic efferent function should be given. These comprise the ganglion-blocking agents, of which only mecamylamine and pempidine are now used in any quantity, methyldopa, and the drugs which block sympathetic fibres at the neuro-effector junction-bretylium, guanethidine, bethanidine, guanoxan, guanoclor, and debrisoquine. Pargyline has an effect similar to these drugs on arterial pressure, ${ }^{7}$ but should not usually be prescribed for the maintenance treatment of hypertensive patients because it is a monoamineoxidase inhibitor, and patients receiving drugs of this type may suffer dangerous reactions after some other drugs or foods. The ganglion-blocking drugs affect parasympathetic as well as sympathetic functions and thus may cause additional side-effects. Few people would now consider them the first choice for the treatment of severe hypertension, though they may be very useful if other drugs fail. Bretylium has now fallen into disfavour because many patients become tolerant of its hypotensive effects.

In the B.M.F. this week Dr. V. Vejlsgaard and his colleagues report a double-blind comparison of four drugsnamely, guanethidine, methyldopa, guanoxan, and guanoclor. Most studies of different ganglion-blocking agents have concentrated on the severity of postural hypotension, and the incidence of side-effects over a relatively short period of time. The present workers found methyldopa the most satisfactory in these respects. In a similar comparison between methyldopa, guanethidine, and pargyline ${ }^{7}$ the same conclusion was reached, though there was much variation between patients. About two-thirds of the patients were better controlled by methyldopa than either of the other drugs, but one-third of them did better on one of the other agents. This merely underlines the fact that no ideal drug exists. Vejlsgaard and his associates have shown convincingly that guanoclor is a difficult drug to use for the maintenance treatment of hypertension, and it seems unwise to employ it unless others fail to give satisfactory results. Though guanoxan performed fairly well in their hands, impaired liver function has now been observed in many patients receiving it, ${ }^{8-10}$ and it may be wise to give it too only if other agents fail.

This leaves methyldopa, guanethidine, bethanidine, and debrisoquine. The last two have not been formally compared with other drugs, but of the first two methyldopa appears to have a marginal advantage. ${ }^{11}$ However, it also has some drawbacks. Between $10 \%$ and $30 \%$ of patients receiving long-term treatment develop a positive reaction to the Coombs test, and a small proportion of these have haemolytic anaemia. ${ }^{12}$ There is also a risk of drug fever and liver damage. ${ }^{13}$ In some patients it is impossible to control the blood pressure with methyldopa, even in combination with a diuretic. Many different remedies will need to be tried in difficult cases, and sometimes a combination of two sym-

1 Leishman, A. W. D., Lancet, 1963, 1, 1284.

2 Hamilton, M., Thompson, E. N., and Wisniewski, T. K. M., ibid., $1964,1,235$.

s Levine, R. J., and Strauch, B. S., New Engl. f. Med., 1966, 275, 946.

- Cooper, E. H., and Cranston, W. I., Lancet, 1957, 1, 396.

Chesrow, E. J., Bernstein, M., Wiess, D., and Marquardt, G. H., Amer. F. med. Sci., 1966, 251, 166.

- Prichard, B. N. C., and Gillam, P. M. S., Brit. med. F., 1964, 2, 725.

Oates, J. A., Seligmann, A. W., Clark, M. A., Rousseau, P., and Lee, R. E., New Engl. f. Med., 1965, 273, 729.

- Montuschi, E., and Lovel, T. W. I., Lancet, 1964, 2, 1339.

Sheps, S. G., Schirger, A., Osmundson, P. J., Kavanaugh, G. J., Fairbairn, J. F., and Burbank, M. K., Mayo Clin., Proc., 1966, 41, 577. 10 Cotton, S. G., and Montuschi, E., Brit. med. \%., 1966, 1, 51 .

1 Johnson, P., Kitchin, A. H., Lowther, C. P., and Turner, R. W. D. johnson, P., Kitchin,

12 Carstairs, K. C., Breckenridge, A., Dollery, C. T., and Worlledge, S. M., Lancet, 1966, 2, 133.

is Sioerdsma, A., in Antihypertensive Therapy, ed. F. Gross, p. 321. 1966. Berlin.

14. Breckenridge, A., and Dollery, C. T., Lancet, 1966, 1, 1074. pathetic blocking agents will give better results than a single one. ${ }^{14}$ Good results depend to a great extent on the care with which the regimen is managed: this is usually more important than the initial choice of drug.

\section{Rubidomycin in Acute Leukaemia}

Rubidomycin is the first antibiotic to show therapeutic effect in management of acute leukaemia in man. It is produced from a strain of Streptomyces coeruleorubidus, and it is active in all forms of acute leukaemia. J. Bernard and his colleagues, ${ }^{1}$ in an extensive clinical trial, have found it useful in the treatment of acute lymphoblastic leukaemia and have also been able to obtain remission in more than half their patients with acute myeloblastic leukaemia. This is the first time that the use of one drug alone has resulted in such a satisfactory remission rate in acute myeloblastic leukaemia, and the duration of the remissions appears to be at least several months.

Several schedules for the administration of rubidomycin are being tried, and it is not yet possible to define the most satisfactory method. It is now agreed, however, that remission should be induced by the shortest possible course and that maintenance therapy is contraindicated because of the drug's toxic effects on the heart. Remissions may be induced by the intravenous administration of the drug dissolved in saline and injected into a fast-flowing infusion. The injection is given daily in a dose of 1 to $2 \mathrm{mg}$. per kilogram body weight per day, the length of the course depending on how well it is tolerated. The maximum dose that should be given is about $20 \mathrm{mg}$. per kilogram body weight, the average dose before side-effects are encountered being 6 to $10 \mathrm{mg}$. per kilogram.

So far the major complications encountered have been cardiotoxicity and bone-marrow aplasia. Toxic effects on the heart first show themselves by tachycardia, which leads rapidly to pulmonary oedema and death. Death from myocardial degeneration induced by rubidomycin has occurred in about $10 \%$ of patients treated so far. ${ }^{12}$ The onset of this complication does not appear to be preceded by electrocardiographic abnormalities, and heart failure when it occurs is of sudden onset and intractable. Its occurrence is related to the total dose given and has been seen in patients given maintenance therapy or when a large dose was required to obtain a remission.

Aplasia of the bone marrow is severe and occurs in a large proportion of patients treated, G. Mathé having noted an incidence as high as $90 \% .^{2}$ It is more likely to occur in those patients who have had a number of chemotherapeutic agents before starting rubidomycin, or in whom bone-marrow smears are not very cellular at the start of therapy. Aplasia commonly arises during the second week of treatment and requires supportive therapy with antibiotics and transfusions of platelets and white cells. The alternative is to nurse the patient in a germ-free environment and to give blood and platelet transfusions when necessary.

Hence rubidomycin is a very powerful therapeutic agent which warrants further trial. Its use at the present time

\footnotetext{
1 Bernard, J., Jacquillat, C., Boiron, M., Najean, Y., Seligmann, M.,

Tanzer, J., Weil, M., and 1.ortholary, P., Presse med., 1967, 75, 951., 